\title{
The Forty-year History of Revenue Management: Bibliometric Analysis
}

\author{
Yun Prihantina Mulyani ${ }^{1}$ \\ ${ }^{1}$ Program Studi Teknik Industri \\ Departemen Teknik Mesin dan Industri, Fakultas Teknik, Universitas Gadjah Mada \\ Jl. Grafika No. 2, Yogyakarta, 55281 \\ email:yun.prihantina@ugm.ac.id \\ doi: https://doi.org/10.31315/opsi.v14i1.4677
}

Received: $19^{\text {th }}$ April 2021; Revised: $11^{\text {th }}$ May 2021; Accepted: $18^{\text {th }}$ May 2021;

Available online: $24^{\text {th }}$ June 2021; Published regularly: June 2021

\begin{abstract}
This paper presents research trends, leading publishers, influential articles, and shifting concerns in the field of Revenue Management for over forty years based on bibliometric analysis. Bibliometric data was retrieved from Web of Science core collection with a well-defined strategy. The data was processed using Network Analysis Interface for Literature Studies Project scripts. Subject-wise and year-wise research trends were presented. The shifting concerns in RM in terms of topic, method, and domain were highlighted using keyword analysis. In general, RM showed an increasing number of published papers with exponential manner every year. The research core in RM covered the three major decisions in RM including pricing, quantity control, and structural decision. It was highlighted that RM's concern has shifted from single-firm decision to be more consumer-and competitioncentric. The data showed that the needs of empirical study and more advanced quantitative methods for complex and real-time problems were urged. In addition, the adoption of RM was extended for industries with semi-flexible capacity. The top influential publishers were Decision Sciences, Operations Research, Management Science, and Management Science Manufacturing \& Service Operations Management.
\end{abstract}

Keywords: revenue management; review; citation network; keyword analysis

\section{INTRODUCTION}

Revenue management (RM) was a relatively emerging topic which has been developed since the 1970s. It involves "allocating right type of capacity to the right kind of consumer at the right price in the right time to maximize revenue or yield" (Kimes, 1989) and also "to the right distribution channel" in the case of mix channel (Hayes \& Miller, 2011). In short, it covers price decisions, capacity or quantity decisions, and structural decisions which explain other supporting schemes for the two decisions above, for example selling format, segmentation mechanism, and terms of trade to offer. Scientific advances in economics, statistics, and operations research and advances in information technology are entailed to supervise the decision-making process. Those advances provide the capability to automate, capture and store data or transactions, to quantify uncertainties, demand, economic conditions, and market response, and to compute or solve complex decision problems. Therefore, multidisciplinary becomes a necessity in this field. For a thorough introduction to revenue management, its history, theory, and application, can be further seen in Talurri \& Ryzin (2004).

The Airline Deregulation Act of 1978 has initiated the development of RM (Talurri \& Ryzin, 2004). The act cut the U.S. Civil Aviation Board (CAB)'s control of airline prices and led to quick change and impulsive innovation in the industry. The initial application of dynamic pricing was made in 1978. The success of RM practice in airline industry inspired the adoption of RM practice in other sectors with conditions: inflexible capacity, perishable products, variable and uncertain demand, and heterogeneous consumers. Some RM adopters are hotels, restaurants, sport and entertainment ticketing to name a few (Ivanov \& Zhechev, 2012; Kimes, 2003; Qiwen, 2010; Talurri \& Ryzin, 2004). 
From then, RM continues to grow to accommodate the changes and create improvement for the better decision-making process and get massive attention from both professional and academic sectors.

Revenue management has been made since the 70 s, but the real study has started in the early 90s. Littlewood, written in 1972, made the first pioneer work about marginal seat revenue, followed by Rohtstein (1974) about overbooking policy and Belobaba $(1987,1989)$ about EMSR (Expected Marginal Seat Revenue) rules. In the late $90 \mathrm{~s}$, some scholars have reviewed this field to formulate its definition, conceptual framework, objectives, application, and advantages. They also defined the characteristics of industries that can be adopters. Some of the authors are Kimes, (1989), Weatherford and Bodily (1992), Lieberman (1993), Jauncey et al. (1995), to name a few. Those papers proposed to promote revenue management theory and positioned the field.

Works in this field published by various disciplines such as operations research, transportation science, and management (Qiwen, 2010). It was because many famous experts of those disciplines had joined this field, and specific scholarly journal in revenue management were not available at that time. Later, Journal of Revenue and Pricing Management (JRPM) was created in 2003, followed by International Journal of Revenue Management (IJRM) in 2007.

In the early 2000 s, many scholars started to do reviews on the progressing works in RM, projected the future research, and identified the future challenges or changes with which RM must cope. Some of them reviewed according to: 1) themes for example service revenue management by Qiwen (2010); 2) type of decisions, methods, and models such as pricing decision by Elmaghraby and Keskinoeak (2002) and quantity decisions by (Klein et al., 2020); 3) industrial types as sample such as airline industry by Pak and Piersma (2002), hotel by Guillet et al. (2015), car rental by Jose et al. (2011), and remanufacturing by Kumar et al. (2016); 4) dimensions for example consumer behavior by Shen and Su (2007), and customer choice model by Strauss et al. (2018). Some of them concerned about the position of revenue management among other management methods such as Boyd and Bilegan (2003). Only a few papers discussed comprehensive overview in Revenue Management. Besides, the contribution made by other disciplines for the development of RM has not been discussed so far.

Most of the review studies applied systematic review, content analysis, or qualitative approaches to identify the progressing research which was relied on authors' individual view. This kind of review method belongs to traditional review methods and is relatively subjective (Zupic and Cater, 2015). However, some bibliometric analysis with advanced methods such as evaluative techniques or relational techniques has been done in other fields such as tourism and hospitality (Köseoglu et al., 2016) in which revenue management became a part of it.

This paper aims at presenting a general bibliometric analysis in revenue management. It provides the analysis on overview of the research trends, leading publishers, and influential articles in the field. It also captures the dynamic changes in RM to identify the core set problems which remain in RM all the time, and upcoming issues due to the changes in business environment, technology advancement, and so on by mapping the topic, methods, and domain/industries mentioned in the articles based on keywords. In addition to this, the contribution of each discipline/research area/research categories toward RM is analyzed.

Different from the former paper that applied systematic review of some selected highly cited publications, we use all articles in revenue management over the years up to 2017 in Web of Science (WoS) database. WoS is wellknown, objective, and the most powerful database in academic research. Many papers collected information through the WoS as it objectively assesses the journals and includes those with the highest standard only. In this paper, we focused on the use of the bibliometric method to evaluate publications in revenue management and did not engage in the criticism of bibliometric methodology. Network Analysis Interface for Literature Studies (NAILS) Project scripts to get the overview of research trends and keyword analysis.

\section{METHOD}

\subsection{Data Collection}

In most of the bibliometric studies, the scholars defined the leading journals to be 
assessed. However, only two journals in RM are listed by Scopus, which are IJRM and JPRM and only JRPM has been included in Web of Science (WoS) with 83 records during the last two years. Therefore, it does not have many papers at this time. It does not include early and pioneer journals in revenue management before 2016. Besides, multidisciplinary in the field must be highlighted since many studies in RM have been published in management science or operations research, economy, management, decision science, computer science, and so on. The data of research publications on RM from the WoS Core Collection were collected by utilizing synonymous names to the practice (Talurri and Ryzin, 2004). Further, we restricted the search to English research articles as our focus was to analyze the research trends in RM. Review papers, book chapter, proceedings are excluded.

\subsection{Data Analysis}

This paper analyses bibliometric data based on a total number of citations and the total number of papers. The most influential articles and authors are identified using three measures, which are in-degree in the citation network, number of citations (only for articles in the dataset), and PageRank score in the citation

Tabel 1. Year-wise overview of articles

\begin{tabular}{|c|c|c|c|c|c|c|c|}
\hline SC & TP & TC & NR & PG & TC/TP & NR/TP & PG/TP \\
\hline 1982 & 1 & 17 & 33 & 14 & 17.00 & 33.000 & 14.00 \\
\hline 1992 & 3 & 547 & 54 & 46 & 182.33 & 18.000 & 15.33 \\
\hline 1993 & 3 & 111 & 29 & 38 & 37.00 & 9.667 & 12.67 \\
\hline 1994 & 3 & 569 & 94 & 41 & 189.67 & 31.333 & 13.67 \\
\hline 1995 & 12 & 506 & 238 & 181 & 42.17 & 19.833 & 15.08 \\
\hline 1996 & 7 & 152 & 121 & 96 & 21.71 & 17.286 & 13.71 \\
\hline 1997 & 10 & 410 & 166 & 120 & 41.00 & 16.600 & 12.00 \\
\hline 1998 & 7 & 294 & 259 & 112 & 42.00 & 37.000 & 16.00 \\
\hline 1999 & 19 & 927 & 419 & 269 & 48.79 & 22.053 & 14.16 \\
\hline 2000 & 19 & 909 & 513 & 315 & 47.84 & 27.000 & 16.58 \\
\hline 2001 & 16 & 491 & 395 & 235 & 30.69 & 24.688 & 14.69 \\
\hline 2002 & 22 & 535 & 583 & 367 & 24.32 & 26.500 & 16.68 \\
\hline 2003 & 29 & 1106 & 806 & 401 & 38.14 & 27.793 & 13.83 \\
\hline 2004 & 22 & 900 & 651 & 367 & 40.91 & 29.591 & 16.68 \\
\hline 2005 & 22 & 718 & 616 & 369 & 32.64 & 28.000 & 16.77 \\
\hline 2006 & 34 & 766 & 910 & 533 & 22.53 & 26.765 & 15.68 \\
\hline 2007 & 68 & 1411 & 1971 & 1062 & 20.75 & 28.985 & 15.62 \\
\hline 2008 & 64 & 1601 & 1796 & 954 & 25.02 & 28.063 & 14.91 \\
\hline 2009 & 89 & 1643 & 2774 & 1407 & 18.46 & 31.169 & 15.81 \\
\hline 2010 & 82 & 1126 & 2619 & 1130 & 13.73 & 31.939 & 13.78 \\
\hline 2011 & 85 & 860 & 3000 & 1279 & 10.12 & 35.294 & 15.05 \\
\hline 2012 & 102 & 928 & 3230 & 1508 & 9.10 & 31.667 & 14.78 \\
\hline 2013 & 91 & 729 & 3091 & 1321 & 8.01 & 33.967 & 14.52 \\
\hline 2014 & 120 & 663 & 4657 & 1887 & 5.53 & 38.808 & 15.73 \\
\hline 2015 & 133 & 480 & 5407 & 2136 & 3.61 & 40.654 & 16.06 \\
\hline 2016 & 184 & 194 & 6637 & 2707 & 1.05 & 36.071 & 14.71 \\
\hline
\end{tabular}

Notes: $\mathrm{PY}=$ publication year; $\mathrm{TP}=$ total papers; $\mathrm{TC}=$ total citations; $\mathrm{NR}=$ number of references; $\mathrm{PG}=$ page counts

search engine in WoS with terms "revenue management", "yield management", "revenue optimi*", "pricing AND revenue optimi*", "revenue AND pricing", and "revenue process optimi*". The system screened title, abstract, author keywords, and keyword plus that contained those terms. Those are other roughly network. The results are sorted by those measurements accordingly. In addition to this, any highly cited papers outside the WoS database are manually added based on cited references. NAILS was utilized for bibliometric studies. It was based on simple statistic method 


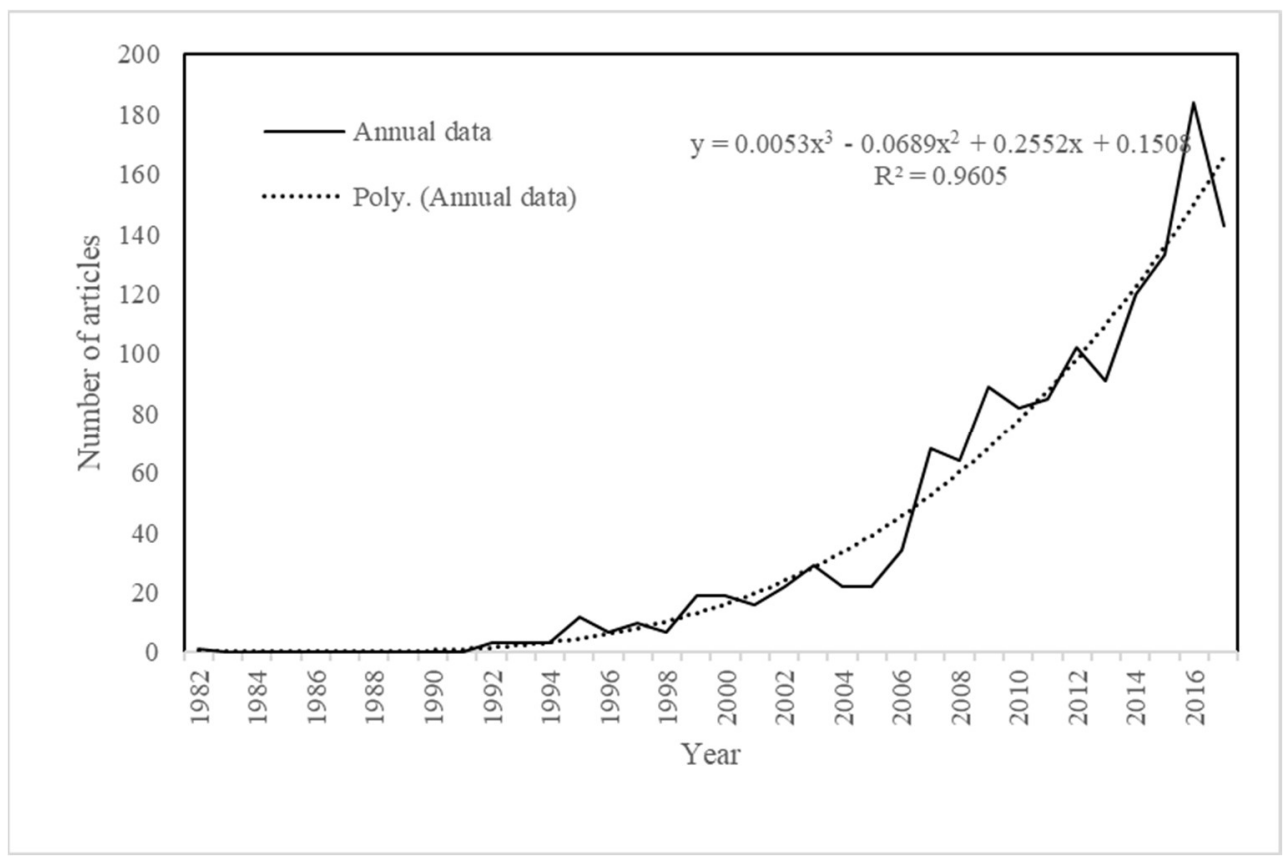

Figure 1. The trend of publications

such as frequency or occurrences for year-wise analysis and subject-wise analysis. It also performed citation network to identify the most influential articles.

This paper also performs the shifting concerns in RM according to the most cited keywords for five-year publications (before 2003, 2003-2007, 2008-2012, and 2013-2017). NAILS resulted in Excel file which contained list of keywords from article's title, author keywords, and keywords Plus. NAILS cannot identify words with similar meaning and group it into one category. Instead, it analyses the exact form of words. For example, "strategic customer" and "strategic consumer" are treated as different keywords. Hence, manual identification of word similarity was done to all possible keywords of 1,390 papers. For example, "inventory allocation", "capacity allocation", "seat allocation", "capacity rationing", "fare class allocation", and "capacity rationing" were grouped into one category, "resource allocation". It intends to get better and more comprehensive results from NAILS project rather than ignoring the possibility of word similarity as resulted from noun derivation, diction, and so on.

\section{RESULTS AND DISCUSSION}

\subsection{Year-wise publication analysis}

From the Web of Science Core Collection, 1,390 scientific articles on revenue management were retrieved over forty years until 2017. Table 1 explains the detailed picture of the distribution of articles, total citation counts, number of references, and page counts by year. The first pioneer work in RM was by Littlewood's in 1972 (Littlewood, 2005), two-level seat reservation and Rothstein's (1974) overbooking policy. Those two papers are not found in WoS Core Collection. The missing data from 1983 to 1991 does not mean discontinued publication in RM. This is the limitation mentioned in the method section. Further analysis included cited references that identified the list of all works referred by the papers in the dataset.

The number of articles had increased significantly every year from less than 10 papers to hundreds papers. The year 2006 showed steep increase in number of articles from 22 (2005) to 34 articles (2006) and the growth continued onwards except for the year 2013 and 2017. This growth indicates the significance and the escalating interests in RM globally. The articles published in the early years, 1992 and 1994, had received highest citation counts per article 
Tabel 1. Year-wise overview of articles

\begin{tabular}{cccccccc}
\hline SC & TP & TC & NR & PG & TC/TP & NR/TP & PG/TP \\
\hline OR/MS & 432 & 9124 & 13246 & 6714 & 21.12 & 30.66 & 15.54 \\
MEF & 239 & 2481 & 7846 & 3512 & 10.38 & 32.83 & 14.69 \\
HTT\&A & 250 & 2536 & 9946 & 3557 & 10.14 & 39.78 & 14.23 \\
CS\&A & 97 & 1737 & 2660 & 1306 & 17.91 & 27.42 & 13.46 \\
Total & 1018 & & & & & & \\
\hline
\end{tabular}

Notes: $\mathrm{SC}=$ subject categories; $\mathrm{TP}=$ total papers; $\mathrm{TC}=$ total citations; $\mathrm{NR}=$ number of references; $\mathrm{PG}=$ page counts $\mathrm{OR} / \mathrm{MS}=$ Operations Research or Management Science; MEF = Management, Economics, and Finance; HTT\&A = Hospitality, Tourism, Transportation Science, and Other Applications, CS\&A = Computer Science and Application

(182.33 and 189.67 respectively) compared to later years. The average citation counts per article before 2006 was quite high at 58.5 compared to the average citation during the period which was 36.82 per article. The number of references cited per article ranged from 9.67 to 41.27. The lowest and the highest scores were in 1993 and 2007 respectively. It made sense as only a few RM's articles published before 1993. The increase was parallel with the growing number in publications. However, it is interesting to note that the trend of cited interest keeps growing in an exponential manner every year.

\subsection{Subject-wise analysis}

Scientific articles in revenue management has been categorised under four WoS subject categories (Table 2). This is relevant to the statement by Qiwen (2010) that this field is multidiciplinary research especially operations research, transportation science, and management. One more category is computer science and its application along with the

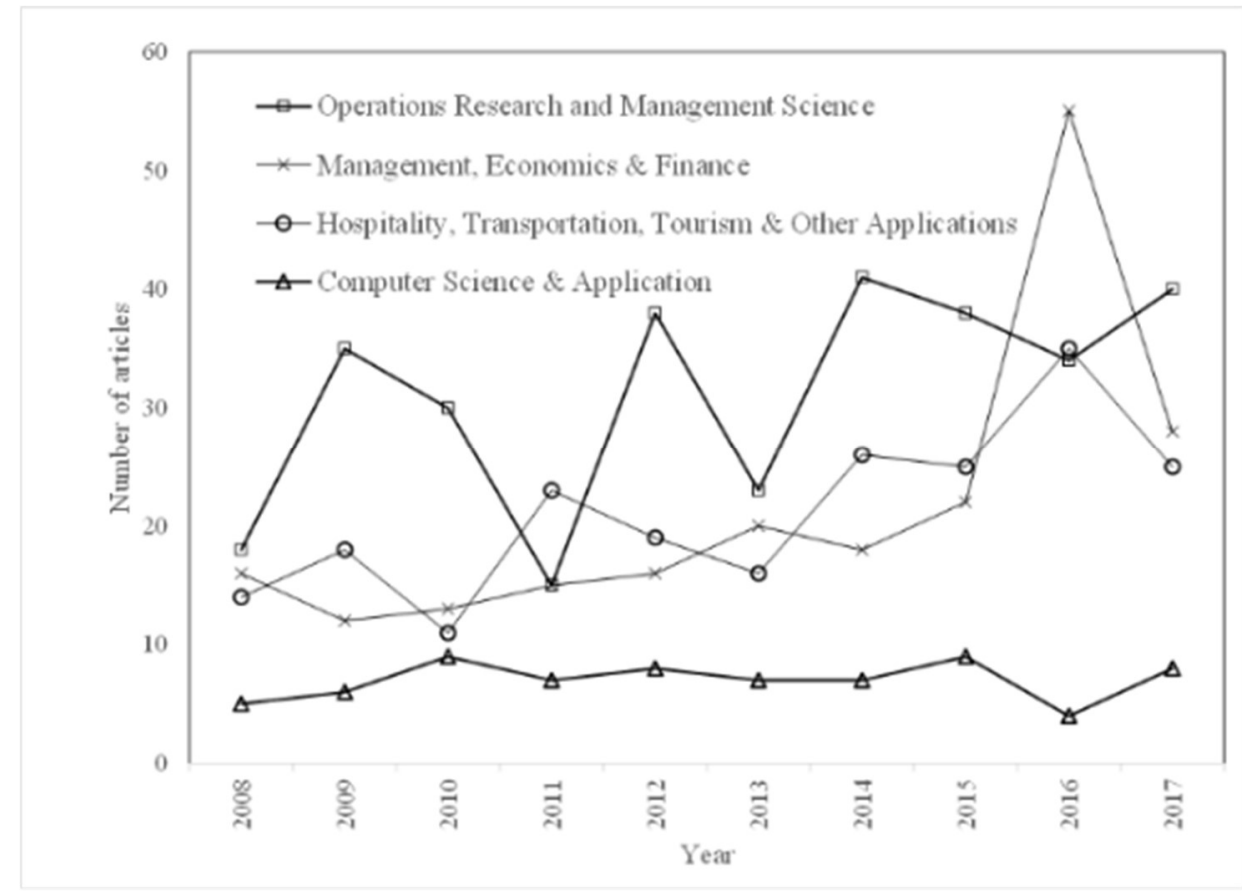

Figure 2. Distribution of articles by WoS categories during 2008-2017

references per article was not commensurate with that of number of articles published. Table 1 and Figure 1 showed that revenue management has become a burning research issue, and the condition where the practice of RM requires computerisation and automation for data collection, computation, and decision support system. 
Operations Research or Management Science was the major category with 432 articles published during 2008-2017 with relatively steady in number of articles published per year. Most of the core articles before 2000s published in OR/MS platforms. The second major subject was Hospitality, Tourism, Transporation Science, and Other Applications (HTT\&A) with slightly differences in number of articles to the third subject of Management, Economics and Finance (MEF), 250 and 239 in total respectively. Both showed increasing trend per year as depicted in Figure 2.

Meanwhile, a few papers published in the caregory of computer science and application (CS\&A) which remained stable during 20082017. The subject category-wise analysis of articles signified that about half of the artiles in revenue management are categorised under the subject of Management Science or Operatons Research. However, the growth in number of articles in the other two subjects, MEF nd HTT\&A, might rise in popularity.

\subsection{Analysis of the most influential articles}

According to three measurement which are in-degree, times cited, and page rank, Table 3 displayed fifty top influential articles all over years along with source title. The scores of indegree and page rank ranged from 14 to 236 and from 0.0000501 to 0.0003937 , respectively. All the 50 publications had received 5,011 citations based on WoS core collections with missing values excluded or 19,348 citations based on Google Scholars (GS). The range was too wide which was 57 (144) to 568 (1461) according to WoS (Google Scholars). However, 19 articles of the top fifty articles received more than 400 citations. Of the top fifty articles, 28\% (14 articles), 18\% (9 articles), 18\% (9 articles), 8\% (4 articles), and 6\% (3 articles) published in Management Science, Operations Research, Transportation Science, Management Science Manufacturing \& Service Operations Management, and Decision Sciences respectively. The majority of the most influential articles in revenue management had published in the discipline of operations research/management science.

Rank resulted in Table 3 was generally parallel to the number of citations. However, some highly cited articles are not in the top list, for example, Kimes (1989), Bitran \&
Mondschein (1997), Su (2007), Aviv \& Pazgal (2008), and Gupta \& Denton (2008). Those papers had very high citations from 520 to 745 citations. This probably because those citations were coming from the same authors as in-degree calculates distinct citing authors rather than simple citation counts. PageRank in Figure 4 showed linear relationship with final rank. The score decreased as the rank increased meaning that the measurement of PageRank was relatively similar to in-degree.

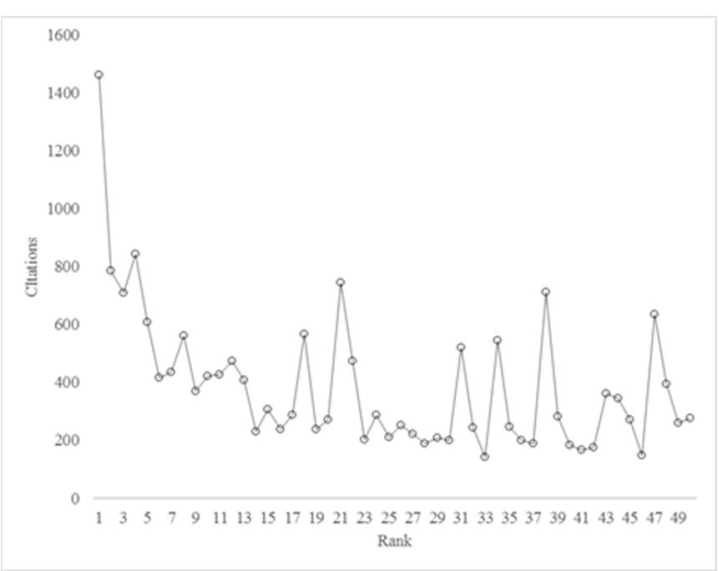

Figure 3. Citation performance

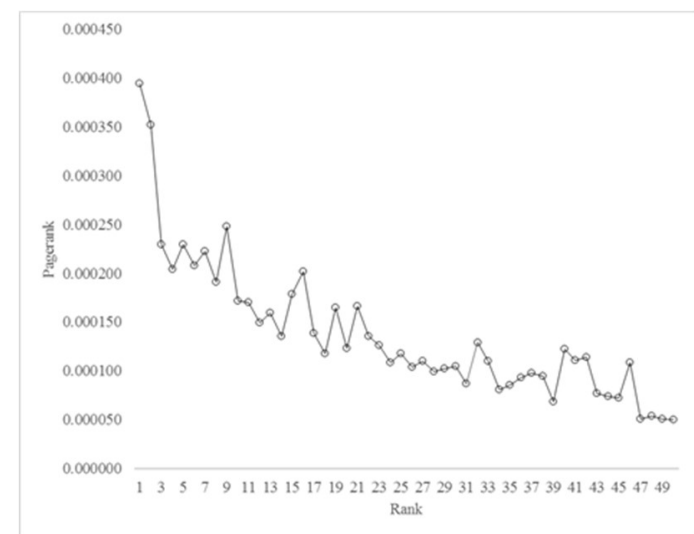

Figure 4. PageRank performance

Figure 5 - Figure 7 showed top salient keywords for terms, methods, and research domains in revenue management. The analysis had been conducted for every five years. The number of citations of earlier publications might be relatively higher than recent publications, for example, times cited for keywords before 2003 ranged from 5 to 2639 and 1 to 869 for 20122017. Hence, times cited scores were normalized in the range of $0-1$ so that the significance could be comparable between periods.

According to our analysis, the top three foci of research in revenue management over the 
years up to 2017 correspond to two main decisions in RM which are pricing-based and quantity-based decisions (Talurri, 2004). However, "resource allocation" showed a downward trend until the last five year while "pricing" continued to rise and dominate until 2017.

The problem of dealing with demand uncertainty and estimation, and optimization were relatively stable. It also happened to any type of structural decision to support the twomain decisions above such as price fencing, booking policy (advance selling, overbooking, no-show, and cancellation), distribution channel, and network RM. Those issues have become foci and long-last topic in revenue management. However, some of favorite keywords before 2003 were no longer discussed or getting very limited attention in later years such as "finite horizon", "revenue losses", "switching time", "welfare maximation", and "coordination". There are some emerging topics in the recent years, which had hardly mentioned before 2003 but getting much attention and showing upward trend until 2017 including consumer behavior, consumer choice, price perception, fairness, and dispersion, competition, and cooperation.

Top salient research method related keywords in Figure 6 were dominated by quantitative methods to support decisionmaking. Heuristic, dynamic/stochastic programming, mathematical programming, and optimization consistently became top three salient methods in revenue management. Specifically, optimization method was increasingly utilized with positive trend until period 2012-2017. The use of utility theory, forecasting methods, markov decision process, and simulation were stable all the time. Game theory, choice model, logit model, conjoint analysis, structural and estimation showed rapid increase from period 2003-2007 until recent years along with the positive trend to consider consumer and competitor's responses in revenue management. Besides, big data analytics, machine learning, and hybrid model. Those were barely discussed in the period before 2003 but reasonably high usage in the last period (20122017).

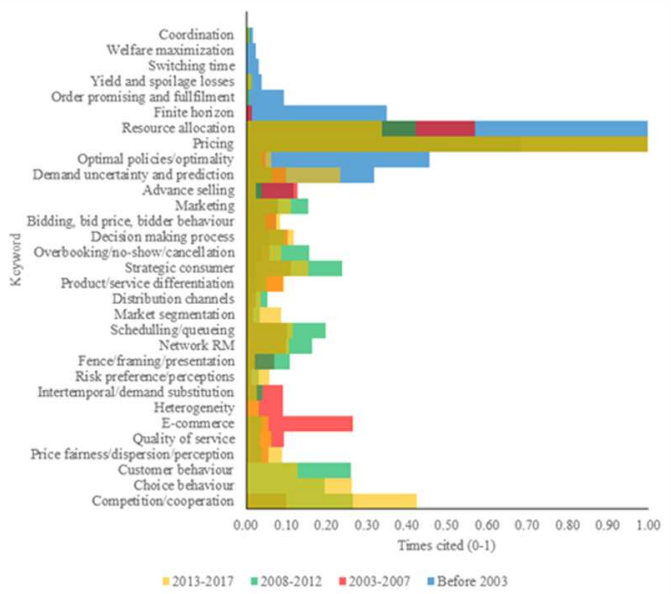

Figure 5. Top salient terms

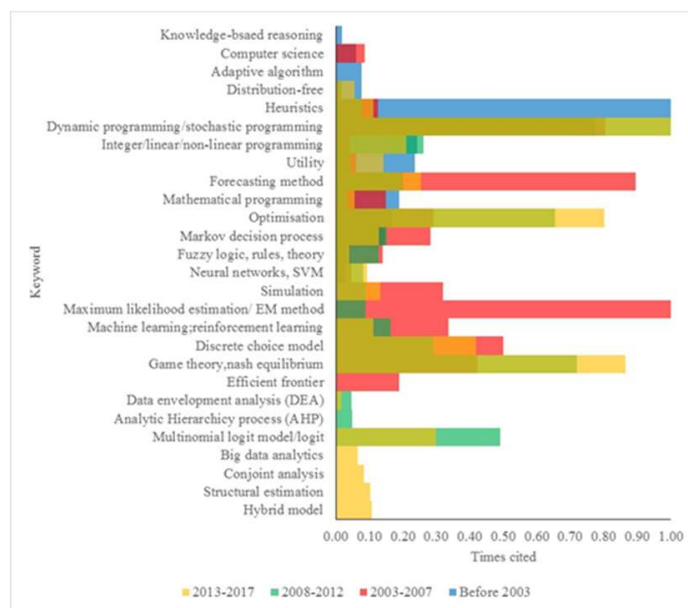

Figure 6. Top salient methods

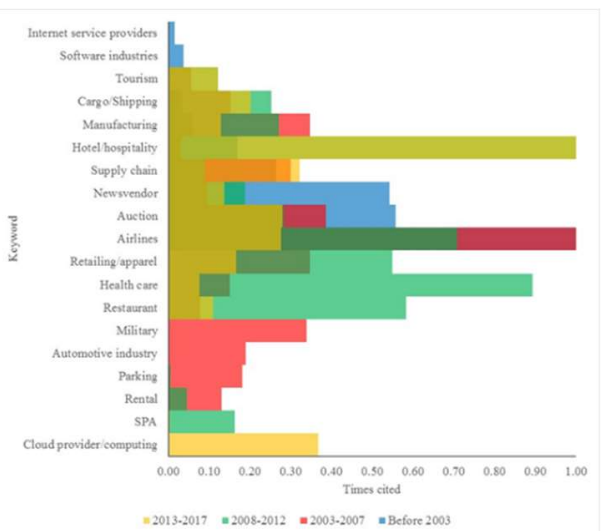

Figure 7. Top salient research domains in revenue management 
Table 3. Top 50 most-influential articles

\begin{tabular}{|c|c|c|c|c|c|c|c|c|}
\hline No. & Authors & Year & Source title & $\begin{array}{c}\text { In- } \\
\text { Degree }\end{array}$ & $\begin{array}{l}\text { Times Cited } \\
\text { (WOS) }\end{array}$ & $\begin{array}{c}\text { Times } \\
\text { Cited (GS) }\end{array}$ & PageRank & Title \\
\hline 1 & $\begin{array}{l}\text { Gallego and } \\
\text { Ryzin }\end{array}$ & 1994 & Management Science & 236 & 537 & 1461 & 0.000394 & Optimal dynamic pricing of inventories with stochastic demand over finite horizons \\
\hline 2 & Belobaba, $\mathrm{P}$ & 1989 & Operations Research & 159 & $275(\mathrm{~A})$ & 786 & 0.000352 & OR Practice-Application of a Probabilistic Decision Model to Airline Seat Inventory Control \\
\hline 3 & $\begin{array}{l}\text { Talurri and Ryzin } \\
\text { Bitran and }\end{array}$ & 2004 & $\begin{array}{l}\text { Management Science } \\
\text { Manufacturing \& Service }\end{array}$ & 153 & 232 & 708 & 0.000229 & Revenue management under a general discrete choice model of consumer behaviour \\
\hline 4 & $\begin{array}{l}\text { Caldentey } \\
\text { Gallego and }\end{array}$ & 2003 & Operations Management & 143 & $\mathrm{~N} / \mathrm{A}$ & 842 & 0.000204 & An Overview of Pricing Models for Revenue Management \\
\hline 5 & Ryzin & 1997 & Operations Research & 140 & 207 & 607 & 0.000229 & A Multiproduct Dynamic Pricing Problem and Its Applications to Network Yield Management \\
\hline 6 & $\begin{array}{l}\text { Lee and Hersh } \\
\text { Brumelle and }\end{array}$ & 1993 & Transportation Science & 101 & $167(\mathrm{~A})$ & 416 & 0.000208 & A Model for Dynamic Airline Seat Inventory Control with Multiple Seat Bookings \\
\hline 7 & McGill & 1993 & Operations Research & 98 & $152(\mathrm{~A})$ & 436 & 0.000222 & Airline Seat Allocation with Multiple Nested Fare Classes \\
\hline 8 & Belobaba, PP & 1987 & Transportation Science & 96 & $178(\mathrm{~A})$ & 562 & 0.000191 & Survey Paper-Airline Yield Management An Overview of Seat Inventory Control \\
\hline 9 & Curry, RE & 1990 & Transportation Science & 95 & $136(\mathrm{~A})$ & 369 & 0.000248 & Optimal Airline Seat Allocation with Fare Classes Nested by Origins and Destinations \\
\hline 10 & Subramanian et al. & 1999 & Transportation Science & 92 & 130 & 421 & 0.000171 & Airline Yield Management with Overbooking, Cancellations, and No-Shows \\
\hline 11 & Talurri and Ryzin & 1998 & Management Science & 91 & 127 & 428 & 0.000170 & An Analysis of Bid-Price Controls for Network Revenue Management \\
\hline 12 & Zhao and Zheng & 2000 & Management Science & 87 & 183 & 473 & 0.000149 & Optimal Dynamic Pricing for Perishable Assets with Nonhomogeneous Demand \\
\hline 13 & Feng and Gallego & 1995 & $\begin{array}{l}\text { Management Science } \\
\text { Manufacturing \& Service }\end{array}$ & 80 & 147 & 409 & 0.000159 & Optimal Starting Times for End-of-Season Sales and Optimal Stopping Times for Promotional Fares \\
\hline 14 & Liu and Ryzin & 2008 & Operations Management & 75 & 90 & 229 & 0.000135 & On the Choice-Based Linear Programming Model for Network Revenue Management \\
\hline 15 & Wollmer, RD & 1992 & Operations Research & 73 & $111(\mathrm{~A})$ & 306 & 0.000178 & An Airline Seat Management Model for a Single Leg Route When Lower Fare Classes Book First \\
\hline 16 & $\begin{array}{l}\text { Brumelle et al. } \\
\text { Bitran and }\end{array}$ & 1990 & Transportation Science & 72 & $97(\mathrm{~A})$ & 238 & 0.000202 & Allocation of Airline Seats between Stochastically Dependent Demands \\
\hline 17 & Mondschein & 1995 & $\begin{array}{l}\text { Operations Research } \\
\text { Journal of Operations }\end{array}$ & 68 & 104 & 288 & 0.000139 & An Application of Yield Management to the Hotel Industry Considering Multiple Day Stays \\
\hline 18 & Kimes, SE & 1989 & Management & 67 & 568 & 568 & 0.000118 & $\begin{array}{l}\text { Yield management: A tool for capacity-considered service firms } \\
\text { Optimal and Approximate Control Policies for Airline Booking with Sequential Nonmonotonic Fare }\end{array}$ \\
\hline 19 & $\begin{array}{l}\text { Robinson, L.W. } \\
\text { Bertsimas and }\end{array}$ & 1995 & Operations Research & 67 & 98 & 239 & 0.000165 & Classes \\
\hline 20 & 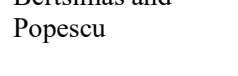 & 2003 & $\begin{array}{l}\text { Transportation Science } \\
\text { 12th AGIFORS }\end{array}$ & 66 & 86 & 271 & 0.000123 & Revenue Management in a Dynamic Network Environment \\
\hline 21 & $\begin{array}{l}\text { Littlewood, } \mathrm{K} \\
\text { Bitran and }\end{array}$ & 1972 & Symposium Proceedings & 65 & $\mathrm{~N} / \mathrm{A}$ & 745 & 0.000166 & Forecasting and control of passenger bookings \\
\hline 22 & $\begin{array}{l}\text { Mondschein } \\
\text { LautenBacher and }\end{array}$ & 1997 & Management Science & 65 & $154(\mathrm{~A})$ & 474 & 0.000136 & Periodic pricing of seasonal products in retailing \\
\hline 23 & $\begin{array}{l}\text { Stidham } \\
\text { Maglaras and }\end{array}$ & 1999 & $\begin{array}{l}\text { Transportation Science } \\
\text { Manufacturing \& Service }\end{array}$ & 61 & 76 & 202 & 0.000126 & The Underlying Markov Decision Process in the Single-Leg Airline Yield-Management Problem \\
\hline 24 & Meissner & 2006 & Operations Management & 60 & 88 & 288 & 0.000109 & Dynamic Pricing Strategies for Multiproduct Revenue Management Problems \\
\hline
\end{tabular}




\begin{tabular}{|c|c|c|c|c|c|c|c|c|}
\hline No. & Authors & Year & Source title & $\begin{array}{c}\text { In- } \\
\text { Degree }\end{array}$ & $\begin{array}{c}\text { Times Cited } \\
\text { (WOS) }\end{array}$ & $\begin{array}{c}\text { Times } \\
\text { Cited (GS) } \\
\end{array}$ & PageRank & Title \\
\hline 25 & Talurri and Ryzin & 1999 & Transportation Science & 57 & $95(\mathrm{~A})$ & 211 & 0.000118 & A randomized linear programming method for computing network bid prices \\
\hline 26 & Feng and Xiao & 2000 & Management Science & 54 & 86 & 253 & 0.000104 & A Continuous-Time Yield Management Model with Multiple Prices and Reversible Price Changes \\
\hline 27 & $\begin{array}{l}\text { Zhang and Cooper } \\
\text { Zhang and }\end{array}$ & 2005 & Operations Research & 54 & 77 & 222 & 0.000110 & $\begin{array}{l}\text { Revenue Management for Parallel Flights with Customer-Choice Behavior } \\
\text { An Approximate Dynamic Programming Approach to Network Revenue Management with }\end{array}$ \\
\hline 28 & Adelman & 2009 & Transportation Science & 54 & 64 & 189 & 0.000099 & Customer Choice \\
\hline 29 & Feng and Xiao & 2000 & Operations Research & 51 & 76 & 209 & 0.000102 & Optimal Policies of Yield Management with Multiple Predetermined Prices \\
\hline 30 & Adelman, D & 2007 & Operations Research & 51 & 65 & 200 & 0.000105 & Dynamic Bid Prices in Revenue Management \\
\hline 31 & $\mathrm{Su}, \mathrm{X}$ & 2007 & Management Science & 50 & 172 & 520 & 0.000087 & Intertemporal Pricing with Strategic Customer Behavior \\
\hline 32 & Glover et al. & 1982 & Interfaces & 50 & $85(\mathrm{~A})$ & 243 & 0.000130 & The passenger-mix problem in the scheduled airlines \\
\hline 33 & Cooper, W & 2002 & $\begin{array}{l}\text { Operations Research } \\
\text { Manufacturing \& Service }\end{array}$ & 49 & 58 & 144 & 0.000110 & Asymptotic Behavior of an Allocation Policy for Revenue Management \\
\hline 34 & $\begin{array}{l}\text { Aviv and Pazgal } \\
\text { Geraghty and }\end{array}$ & 2008 & Operations Management & 47 & 158 & 544 & 0.000081 & Optimal Pricing of Seasonal Products in the Presence of Forward-Looking Consumers \\
\hline 35 & $\begin{array}{l}\text { Johnson } \\
\text { Karaesmen and }\end{array}$ & 1997 & Interfaces & 47 & 84 & 247 & 0.000085 & Revenue Management Saves National Car Rental \\
\hline 36 & Ryzin & 2004 & Operations Research & 47 & 81 & 201 & 0.000093 & Overbooking with Substitutable Inventory Classes \\
\hline 37 & $\begin{array}{l}\text { Miranda, BJ } \\
\text { Federgruen and }\end{array}$ & 2009 & Operations Research & 47 & 60 & 188 & 0.000098 & A Column Generation Algorithm for Choice-Based Network Revenue Management \\
\hline 38 & Kimes and Wirtz & 1999 & $\begin{array}{l}\text { Operations Research } \\
\text { Journal of Service } \\
\text { Research }\end{array}$ & 47 & 341 & 711 & 0.000094 & $\begin{array}{l}\text { Combined pricing and inventory control under uncertainty } \\
\text { Has revenue management become acceptable? Findings from an international study on the perceived } \\
\text { fairness of rate fences }\end{array}$ \\
\hline 40 & Pfeifer, PE & 1989 & $\begin{array}{l}\text { Decision Sciences } \\
\text { European Journal of }\end{array}$ & 46 & $68(\mathrm{~A})$ & 184 & 0.000123 & The airline discount fare allocation problem \\
\hline 41 & $\begin{array}{l}\text { Alstrup et al. } \\
\text { Belobaba and } \\
\text { Weatherford }\end{array}$ & 1986 & Operations Research & 44 & $75(\mathrm{~A})$ & 166 & 0.000111 & $\begin{array}{l}\text { Booking policy for flights with two types of passengers } \\
\text { Comparing Decision Rules that Incorporate Customer Diversion in Perishable Asset Revenue } \\
\text { Management Situations }\end{array}$ \\
\hline 43 & Liu et al. & 2008 & Management Science & 39 & 123 & 362 & 0.000077 & Strategic Capacity Rationing to Induce Early Purchases \\
\hline 44 & $\begin{array}{l}\text { Xie and Shugan } \\
\text { Desiraju and }\end{array}$ & 2001 & Marketing Science & 34 & 157 & 344 & 0.000074 & Electronic Tickets, Smart Cards, and Online Prepayments: When and How to Advance Sell \\
\hline 45 & Shugan & 1999 & Journal of Marketing & 31 & 90 & 271 & 0.000072 & Strategic Service Pricing and Yield Management \\
\hline 46 & Rothstein, M & 1974 & Decision Sciences & 31 & N/A & 149 & 0.000109 & Hotel overbookings as a markovian sequential decision process \\
\hline 47 & $\begin{array}{l}\text { Gupta and Denton } \\
\text { Paschalidis and }\end{array}$ & 2008 & $\begin{array}{l}\text { IIE Transactions } \\
\text { IEEE/ACM Transactions }\end{array}$ & 16 & 234 & 636 & 0.000051 & Appointment scheduling in health care: Challenges and opportunities \\
\hline 48 & Tsitsiklis & 2000 & on Networking & 14 & 159 & 395 & 0.000054 & Congestion-dependent pricing of network services \\
\hline 49 & $\begin{array}{l}\text { Patrick et al. } \\
\text { Dana, J }\end{array}$ & $\begin{array}{l}2008 \\
1999\end{array}$ & $\begin{array}{l}\text { Operations Research } \\
\text { Rand Journal of } \\
\text { Economics }\end{array}$ & $\begin{array}{l}14 \\
14\end{array}$ & $\begin{array}{c}102 \\
94\end{array}$ & $\begin{array}{l}259 \\
276\end{array}$ & $\begin{array}{l}0.000051 \\
0.000050\end{array}$ & $\begin{array}{l}\text { Dynamic Multipriority Patient Scheduling for a Diagnostic Resource } \\
\text { Equilibrium Price Dispersion under Demand Uncertainty: The Roles of Costly Capacity and Market } \\
\text { Structure }\end{array}$ \\
\hline
\end{tabular}


Revenue management had been applied in many domains or industrial types (Figure 6). Period before 2003, airline, retailing, and auction were considered as top three case studies in the field. However, the last ten years, publications put much attention to the application of RM in hotel/hospitality. In addition to this, during 2007-2012, RM for restaurant and health care system were notable and reached the peak. It is interesting to note that RM has been widely used in service industries. In addition to this, the adoption of RM began to be applied to industries with semi-flexible capacity such as parking, car rental, and restaurant where capacity is highly correlated or depending on the time of use. This requires adjustment to take the advantage of RM application.

According to our analysis above, revenue management are now more consumer-centric and put more attention to external responses such as competition or alliances with other players. This is accordance with Noone et al. (2011) who notified that the topics in RM has shifted from single firm problems to more understandings on consumer and competition. Consumer-centric addresses buying behavior, preferences, expectation, and responses while business relation include competition, alliance, cooperation, and any form of business relationship. How to understand competition and consumer and then to utilize such information to develop better revenue management system are still questioned and under discussion. This brought the emergence research methods such as game theory, choice model, and logit and conjoint analysis in the past decade. The trend also naturally expects more empirical evidence rather than conceptual framework or numerical experiment (Gonsch et al., 2013). It associates with the advanced technology applied in RM system that allows real-time data collection. It is not surprising that the use of big data analysis or machine learning were increasing recently. It demands the researchers in this field to provide more sophisticated methods to deal with complexity and real-time problems.

\section{CONCLUSION}

This paper presented a general bibliometric analysis in revenue management and provided an overview of the research trends, leading publishers, and influential articles in the field by utilizing NAILS project scripts with citation network analysis and three indicators for ranking. It also highlighted the shifting concerns in topics, methods, and research domains based on keywords analysis. The results were generated from WoS Core Collection database. The main contribution of this paper is the formulation of search strategy for paper collection in WoS, the use of relation techniques (citation network through NAILS), and the use of keyword analysis.

The increasing attention on this field was remarkable in exponential manner every year. Most articles in revenue management were published in operations research/management science platforms and even $60 \%$ of the most influential articles were published in Management Science, Operations Research, Management Science Manufacturing \& Service Operations Management, and Decision Sciences. The results of keyword analysis supported other review papers in RM with systematic review. Revenue management are now more consumer and competition-centric rather than focusing on single-firm problems. Along with sophisticated technology applied in RM system, research in this field demands empirical study and more advanced quantitative methods to deal with complexity and real-time problems. Besides, it is interesting to note that the adoption of RM for semi-flexible capacity requires rigorous reconsideration and adjustment.

However, it is worth noting that there are several limitations of this paper. First, this study is based on WoS Core Collection database in which only one specific journal in the field is recognized, JRPM since 2016 with 83 records. Thus, only a few papers are included in the analysis and the number of citations is also affected. In fact, JRPM and IJRM have published 452 articles since 2009 and 173 articles since 2007, respectively. Second, papers in RM have spread in many platforms. Hence, it is quite difficult to identify the most popular journals to be assessed. This is the reason why this paper used search strategy for data collection, and it could not be proven that the datasets are considerably representative. However, this issue is tackled by the use of cited references to detect other works outside WoS database. For future research, expert judgement 
for classifying the top journals in $\mathrm{RM}$ is suggested.

\section{REFERENCES}

Aviv, Y., and Pazgal, A. (2008). Optimal Pricing of Seasonal Products in the Presence of Forward-Looking Customers. Manufacturing and Service Operations Management, 10(3), 339-359.

Belobaba, P.P. (1987) Airline yield management: An overview of seat inventory control. Transportation Science 21(2): 63-73.

Belobaba, P. P. (1989). Application of probabilistic decision model to airline seat inventory control. Operations Research, 37(2), 183-198.

Bitran, G. R., Mondschein, S. V. (1997). Periodic pricing of seasonal products in retailing, Management Science, 43, 6478.

Boyd, E. A., and Bilegan, I. C. (2003). Revenue Management and E-Commerce. Management Science, 49(10), 13631386.

Elmghraby W.,P.Keskinocak. (2002) Dynamic Pricing: research overview, current Practices and future directions. Georgia Institute of Technology.

Gönsch, J., Klein, R., Neugebauer, M., and Steinhardt, C. (2013). Dynamic pricing with strategic customers. Journal of Business Economics, 83(5), 505-549.

Guadix, J., Onieva, L., Muñuzuri, J., Cortés, P. (2011). An overview of revenue management in service industries: an application to car parks. The Service Industries Journal, 31(1), 91-105.

Guillet, B.D., Mohammed, I. (2015). Revenue management research in hospitality and tourism: A critical review of current literature and suggestions for future research. International Journal of Contemporary Hospitality Management, 27(4), 526-550.

Gupta, D., Denton, B. (2008). Appointment scheduling in health care: Challenges and opportunities, IIE Transactions, 40(9), 800-819

Hayes, D. K., and Miller, A. (2011). Revenue Management for the Hospitality Industry. Journal of Revenue and Pricing Management, 11(4), 479-480.
Ivanov, S., and Zhechev, V. (2012). Hotel revenue management - a critical literature review. Tourism Review, 60(2), 175-197.

Jauncey S, Mitchell I, Slamet P. (1995). The meaning and management of yield in hotels[J]. International Journal of Contemporary Hospitality Management, 7(4):23-26.

Kimes, S. E. (1989). The Basics of Yield Management. Cornell Hotel and Restaurant Administration Quarterly, 30(3), 14-19.

Kimes, S.E. (2003). Revenue Management: A Retrospective. Cornell Hotel and Restaurant Administration Quarterly, 44(5), 131-138.

Klein, R., Koch, S., Steinhardt, C., Strauss, A.K. (2020). A Review of Revenue Management: Recent Generalizations and Advances in Industry Applications. European journal of operational research, 284 (2), 397-412.

Köseoglu, M.A., Rahimi, R., Okumus, F., Liu, J. (2016). Bibliometric studies in tourism. Annals of Tourism Research, 61, 180198.

Kumar, R., Ramachandran, P. (2016). Revenue management in remanufacturing: perspectives, review of current literature and research directions. International Journal of Production Research, 54(7), 2185-2201.

Lieberman, W. H., 1993, Debunking the myths of yield management. The Cornell Hotel and Restaurant Administration Quarterly, 34(1):34- 4.

Littlewood, K. (2005). Special Issue Papers: Forecasting and control of passenger bookings. Journal of Revenue Pricing Management, 4(2005), 111-123.

Noone, B.M., McGuire, K.A., Rohlfs, K.V. (2011). Social media meets hotel revenue management: Opportunities, issues and unanswered questions. Journal of Revenue and Pricing Management, 10(4), 293-305.

Pak, K., Piersma, N., 2002. Overview of OR techniques for airline revenue management. Statistica Neerlandica 56 (4), 480-496.

Qiwen, J., Weijun, Z., and Youyan, H. (2010). Revenue Management in the Service Industry: Research Overview and 
Prospect. International Conference on Management and Service Science (MASS), 1-5.

Rothstein, M., 1974. Hotel overbooking as a markovian sequential decision process. Decis. Sci. 5, 389-404.

Shen, Z. M., and Su, X. (2007). Customer Behavior Modeling in Revenue Management and Auctions: A Review and New Research Opportunities. Production and Operations Management, 16(6), 780-790.

$\mathrm{Su}$, X. (2007). Intertemporal Pricing with Customer Behavior. Management Science, 53(5), 726-741.

Strauss, Arne K, Robert Klein, and Claudius Steinhardt. (2018). A Review of ChoiceBased Revenue Management: Theory and
Methods. European journal of operational research, 271 (2), 375-387.

Talurri, K. T., and Ryzin, G. J. Van. (2004). The Theory and Practice of Revenue Management. Boston: Kluwer Academic Publishers.

Weatherford, L., \&Bodily, E. S. (1992). A taxonomy and research overview of perishable- asset revenue management: Yield management, overbooking, and pricing. Operation Research, 40(5), 831843.

Zupic, I., Cater, T. (2015). Bibliometric Methods in Management and Organization, Organizational Research Methods, 18(3), 429-472. 